\title{
Contribuições para o planejamento e a gestão urbana: a experiência do projeto vida no bairro - Francisco Beltrão (PR)
}

Contributions to the planning and urban management: the experience of the projeto vida no bairro - Francisco Beltrão (PR)

\author{
Marcos Aurelio Saquet ${ }^{1}$ \\ Luiz Carlos Flávio ${ }^{2}$
}

\section{Resumo}

Neste texto, resgatamos, avaliamos e socializamos as principais características e os resultados obtidos no Projeto Vida no Bairro (PVB), iniciativa de pesquisa e extensão universitária da qual participamos ativamente entre 2002 e 2006, em parceria com várias pessoas de diferentes instituições da cidade de Francisco Beltrão (PR). Foi um processo desafiador, instigante e gratificante, pois conseguimos nos mobilizar e contribuir diretamente com a conquista de melhores condições de vida, num movimento de luta por um território de vida mais justo para a população urbana com a qual trabalhamos, conforme o leitor poderá verificar ao longo deste texto.

Palavras-chave: Práxis; Cidade; Desenvolvimento; Território.

\begin{abstract}
In this paper, we rescued, socialize and evaluate the main characteristics and the results obtained in the Projeto Vida no Bairro (PVB), research and university extension initiative in which we participated actively between 2002 and 2006, in partnership with various people from different institutions in the city of Francisco Beltrão (PR). It was a challenging, exciting and rewarding process because we could mobilize and contribute directly to the achievement of better living conditions, in a fighting movement for a fairer territory of life for the urban population we work with, as the reader can verify throughout this text.
\end{abstract}

Key-words: Praxis; City; Development; Territory.

\section{Introdução}

Inicialmente, é fundamental afirmar que este texto é resultado da nossa práxis num projeto de pesquisa e extensão, problemática diretamente vinculada aos processos de desenvolvimento local. Assim, estamos socializando e colocando em debate alguns dos resultados que obtivemos, entre 2002 e 2006, no Projeto Vida no Bairro (PVB), efetivado a partir de uma iniciativa singular

\footnotetext{
${ }^{1}$ Professor da Unioeste - Francisco Beltrão. E-mail: saquetmarcos@hotmail.com.

${ }^{2}$ Professor da Unioeste - Francisco Beltrão. E-mail: lucaflavio@gmail.com.
} 
de extensão universitária, efetivada no âmbito da Universidade Estadual do Oeste do Paraná Campus de Francisco Beltrão, envolvendo vários parceiros.

Dado o lastro temporal no qual a experiência aqui posta em tela foi realizada, numa primeira impressão, a menção a ela pode parecer algo desatualizado. Porém, face a um amadurecimento que temos vivenciado nos debates efetivados no âmbito do Geterr (Grupo de Estudos Territoriais), bem como em outros espaços de estudos e atividades acadêmicas (aulas na graduação e/ou pósgraduação, atividades de extensão universitária, debates em eventos etc.), esta é a primeira vez que retomamos essa experiência para reflexão. Justamente porque julgamos relevante refletir, neste momento, sobre esta importante temática que aflora como pertinente e necessária para o avanço do debate envolvendo iniciativas desta natureza, ou seja, projetos identificados com ações que ajudem a problematizar e jogar luzes sobre limites e possibilidades existentes, na realidade brasileira, para o planejamento e a gestão urbana, com nossa participação em projetos realizados por universidades, a exemplo da experiência que apresentaremos.

Desse modo, o resgate da experiência representada pela realização do Projeto Vida no Bairro se põe, a nosso ver, como relevante e importante, uma vez que nos permite debater e analisar avanços e limites encontrados durante o projeto, numa espécie de autoavaliação. Tal exercício pode servir para qualificar outras atividades de pesquisa e extensão que nós e outras pessoas possamos realizar atualmente.

O objetivo geral do Projeto Vida no Bairro foi contribuir diretamente no processo de conquista de melhores condições de vida PARA e COM os moradores do bairro São Francisco, situado na periferia pobre da cidade de Francisco Beltrão (PR). Naquela oportunidade, estudamos e trabalhamos com 144 famílias, somando o total de 533 pessoas envolvidas direta e indiretamente no projeto.

Objetivando efetivar um trabalho pautado por vínculos de solidariedade e participação em prol do desenvolvimento da população em questão ${ }^{3}$, as atividades foram dinamizadas por várias parcerias: Unioeste - Francisco Beltrão ${ }^{4}$, Sindicato dos Empregados no Comércio, Sindicato dos Trabalhadores na Indústria e Vestuário, Sindicato dos Trabalhadores em Transporte Rodoviário, Sindicato dos Trabalhadores Rurais, Sindicato dos Engenheiros, União Brasileira de Estudantes

\footnotetext{
${ }^{3} \mathrm{Na}$ acepção ora empregada, desenvolvimento se refere a ações, conhecimentos, planejamentos (urbano, regional etc.) postos em prática com o fito de superar problemas que afligem as populações, visando patamares mais adequados de participação nas decisões políticas, melhor qualidade de vida, bem como o aumento significativo de justiça social (SOUZA, 2006). Para Oth (1997, p. 88), desenvolvimento é movimento que busca superar problemas de estagnação (como a social), colocando-se como "perpétua capacidade de evoluir [...]".

${ }^{4}$ Os docentes e/ou estudantes da Universidade Estadual do Oeste do Paraná que ajudaram a efetivar o Projeto Vida no Bairro tinham vínculos com cursos de graduação bastante diversos: Geografia, Administração, Economia Doméstica, Ciências Econômicas e Direito.
} 
Secundaristas, Associação dos Professores do Estado do Paraná, Igreja Católica, Assembleia de Deus, Pastoral da Criança, Terceira Idade, Grupo de Jovens do Bairro São Francisco, Clube de Mães, Associação de Moradores do Bairro São Francisco, Assesoar (Associação de Estudos, Orientação e Assistência Rural) e a Prefeitura Municipal de Francisco Beltrão, consoante publicamos em Pacífico, Flávio e Saquet (2005). Portanto, as ações efetivadas e que evidenciamos como nossa contribuição para o planejamento e para a gestão urbana é resultado da nossa atuação conjunta com um grupo de parceiros envolvendo, evidentemente, as famílias de um bairro periférico da cidade de Francisco Beltrão.

Em nossa concepção da relação universidade-sociedade, os processos de planejamento e gestão são entendidos como uma problemática de desenvolvimento vinculada a uma práxis centrada no ensino, na pesquisa e na extensão compreendidos como aspectos indissociáveis da vida prática das populações. Assim sendo, tal práxis, envolvendo a relação teoria-prática, em que conhecimento (científico/popular) e a vida cotidiana da população entram em um processo de realização, a partir de ações concretas, pode ser doravante denominada cooperação voltada para o desenvolvimento territorial com autonomia decisória, por parte dos sujeitos envolvidos. A partir desse entendimento, nossa opção foi e permanece sendo a de trabalhar com as pessoas estudadas, empreendendo esforços para subsidiar da melhor maneira possível a conquista de melhores condições de vida para as populações que habitam, no caso, o bairro São Francisco, em Francisco Beltrão (PR).

Essa opção deriva de uma Geografia voltada para a cooperação e para o desenvolvimento dialógico e participativo, envolvendo elementos de ordem social e territorial. Concepção esta que aponta para o necessário envolvimento da universidade com atitudes e ações políticas que contribuam para o desenvolvimento social, valorizando a criatividade humana; a preservação do ambiente, das identidades e pluralidades sociais; o resgate e disseminação dos conhecimentos populares, os quais podem contribuir de modo importante para interações humanizadoras das relações no âmbito da cidade. Consideramos tais aspectos fundamentais para fomentar práticas políticas direcionadas à tentativa contínua de lutar contra os sistemas que, via de regra, opõem-se ao desenvolvimento territorial das populações, coadunados que são com os interesses conexos à reprodução ampliada do capital (DANSERO, 2008; SAQUET, 2011a, 2011b; SAQUET, DANSERO e CANDIOTTO, 2012).

De acordo com o exposto, uma das premissas tomadas aqui como fundamentais refere-se à aspiração e ao entendimento de que o trabalho acadêmico (envolvendo ensino, pesquisa, extensão como aspectos inextricáveis) pode se colocar como importante componente de ações devotadas à justiça social e ao bem-estar do povo, juntamente com a valorização do homem como sujeito 
político numa práxis em favor do pensamento crítico e da autonomia das populações e, por conseguinte, da efetiva transformação social tão cara a um rol considerável de pensadores críticos das estruturas e forças que concorrem para a construção da sociedade em ininterrupto movimento de (re)produção (MARX, 1991; VAZQUEZ, 1990 [1977]; FREIRE, 2011 [1974] e 2011 [1996]; SANTOS, 2000).

Assim, assumimos a postura segundo a qual o trabalho acadêmico pode ser elemento fertilizador de uma relação teoria-prática fundamental para o avanço em direção a um patamar de consciência acerca dos problemas e dramas vividos pelas populações. Avanço este atento à necessidade de formulação de pensamentos e experiências capazes de mobilizar a sociedade em direção a possíveis soluções, de modo a corroborar e consolidar práticas sociais cristalizadoras de uma condição cada vez mais cidadã para o povo. Condição cuja marca seja, em essência, a de contribuir para o pensamento que não seja divorciado da ação estimuladora da democratização dos direitos sociais, no sentido de que estes sejam estendidos às populações notadamente mais pobres da sociedade (SANTOS, 1993).

Outra premissa das nossas ações, e que necessariamente se articula com os aspectos anteriormente mencionados, refere-se à opção de trabalhar com a relação espaço-território, categorias geográficas cujas dimensões são aqui compreendidas como intimamente relacionadas entre si, conforme descreveremos a seguir. Para Santos (1997), o espaço é resultante da relação homem-natureza, sendo o espaço essencialmente produzido por homens, firmas e instituições, nas intrincadas relações sociais que o delimitam.

O espaço contempla intercâmbios que envolvem qualidades e atributos pertinentes a múltiplas relações e dimensões: econômicas, culturais, políticas, científicas, tecnológicas, educacionais, amorosas, lúdicas, bem como as esferas referentes aos sonhos, esperanças, crenças religiosas, valores, ideologias, mitologias etc., isto é, todas as ações e representações presentes no cotidiano que perfazem a história humana.

Envolvendo todas as motivações e expressões humanas, o espaço acumula ações e infraestruturas as quais se transformam no tempo, face ao concurso de eventos capazes de provocar metamorfoses na relação homens-natureza. As infraestruturas, por sua vez, são condicionadas por tal relação e, ao mesmo tempo, condicionam em cada tempo e lugar específico todas as ações posteriores da sociedade.

Outro aspecto precisa ser levado em conta na dinâmica da construção do espaço dada especificamente no âmbito da cidade. Referimo-nos ao fato de que, para compreender a cidade, é fundamental considerar que ela é, em essência, expressão das lutas travadas entre as diferentes 
classes sociais. Em sua organização, de um lado temos as classes despossuídas que, não tendo posses ou propriedades (terras, máquinas etc.) para sobreviver, precisam vender sua força de trabalho às classes que detêm os meios de produzir as coisas, valores, alimentos, habitações, vestuário etc. Sendo lócus de convergência de todas as produções, intercâmbios e trocas humanas, as cidades são centros, ao mesmo tempo, econômico (produtivo), financeiro, administrativo, comercial, religioso, intelectual, político e, sobretudo, centros de poder, decisões e controle sobre as formas como as pessoas vivem e irão viver: morar, trabalhar, ter (ou não) saúde, educação, transporte, lazer etc. na cidade (LEFEBVRE, 1991; 2008a [1972]; BEAUJEU-GARNIER, 1997; WILLIAMS, 2011 [1973]).

A cidade capitalista moderna é marcada por tensões, conflitos, disputas, produtoras de diferenciações e demarcações territoriais de classes que impetram agregações, coesões e segregações balizadoras da vida das populações na realização cotidiana da dialética espaço-sociedade (CARLOS, 2007; SANTOS, 1993).

Dessa maneira, envolvendo (e sendo envolvida por) relações de poder, redes, identidades, diferenças e desigualdades, a cidade se substantiva como lócus principal do urbano hodierno. E, especificamente, como um importante território, justamente por ter múltiplos significados inerentes aos processos sociais e espaciais traduzidos em suas diversas divisões e limites (re)criados pelos homens nos embates de grupos, classes sociais e instituições.

Também estão presentes, no âmbito da cidade, intensas e distintas relações entre o urbano e o rural, com diferentes formas e conteúdos integrados, relacionados, complementando-se (LEFEBVRE, 1995 [1969] e 1991). Há diversidade, heterogeneidade e unidade entre os espaços rural e urbano, formando territórios sobrepostos e articulados entre si.

O território tem, assim, alguns significados específicos: i) é apropriado e dominado no processo de valorização do capital, envolvendo redes e malhas (INDOVINA e CALABI, 1974); ii) é apropriado e produzido em diferentes níveis escalares (MAGNAGHI, 1976; DEMATTEIS, 1985) e por meio das territorialidades, coloca-se como processo social centrado em relações de poder e nas identidades (RAFFESTIN, 1977, 1993 [1980], 1986; SAQUET, 2007 e 2011a); iii) tem um caráter histórico, relacional e reticular (transescalar), traduzido numa geografia reticular (DEMATTEIS, 1985) ou numa complexa trama territorial trans e multiescalar (DEMATTEIS, 1985 e 2001).

Para Lefebvre (2008b [1970]), a cidade é forma urbana que necessariamente comporta redes (de trocas, comunicações). Os territórios nela presentes abrangem objetos e signos cingidos por justaposições, superposições e oposições que apontam para uma dialética de particularidades- 
-diferenças, motivando lutas e conflitos. As necessidades da vida social estão em constante confronto com interesses capitalistas que planejam domínios espaciais na cidade.

Assim, como adequadamente sintetizou Quaini (1978), o território é construído socialmente, planejado, com significados concretos impressos pelas gentes em seus locais de vida, numa relação dialética e contraditória com os interesses do capital. É em função de planejamentos voltados aos interesses das corporações nas cidades que Arantes (2000) assevera que estas são produzidas sob a lógica da geração de lucros para as empresas. Tornam-se, assim, máquina de fazer riqueza. Diante disso, aos grupos/populações excluídos resta se organizarem a fim de conseguir conquistas referentes a melhorias em suas condições de existência.

Desse modo, as cidades são, por excelência, territórios privilegiados também de grupos que buscam efetivar estratégias territoriais que contribuam para melhorar a vida das populações, garantindo-lhes o exercício de cidadania, buscando efetivá-la como exercício consciente e efetivo de direitos e deveres, no âmbito social, com a participação consciente das pessoas (cidadãos) nas decisões indutoras de qualidade de vida e autonomia para os grupos sociais.

Gadotti (2006, p. 134) sintetiza a ideia de cidadania como "exercício da democracia"5, envolvendo:

- direitos civis, como segurança e locomoção;

- direitos sociais, como trabalho, salário justo, saúde, educação, habitação etc.;

- direitos políticos, como liberdade de expressão, de voto, de participação em partidos políticos e sindicatos etc.

Consoante Gadotti (2006), a construção de uma cidade e de seus cidadãos para o exercício da cidadania implica não na adoção de soluções imediatas ou imediatistas, principalmente vinculadas ao clientelismo, mas em ações balizadas na adoção de uma compreensão analítica, reflexiva e formativa dos cidadãos, de modo a estarem preparados para contribuírem diretamente na criação de soluções para os problemas e desafios do cotidiano contemporâneo.

Para o autor, todos somos sujeitos responsáveis pela melhoria da cidade, podendo contribuir para a construção de uma sociedade humanizada, emancipada e solidária: "Existem muitas energias sociais transformadoras que ainda estão adormecidas por falta de um olhar educativo sobre a cidade. Esse é o objeto da pedagogia da cidade" (GADOTTI, 2006, p. 139), a qual se resume na ideia de que todos podem participar da construção e reconstrução permanente objetivando a edificação de uma cidade melhor.

\footnotetext{
${ }^{5}$ A acepção de democracia pode ser ligeiramente definida como práticas políticas “[...] que enfatizam e estimulam a cidadania e a participação popular no processo decisório e na definição das prioridades [...]", tal como definido por Teixeira (2004, p. 29).
} 
A experiência por nós abraçada na realização do Projeto Vida no Bairro (PVB), a qual descreveremos a seguir, aponta para uma tentativa nessa direção. Em tal construção, a universidade tem um papel muito importante.

\section{Revisitando o Projeto Vida no Bairro}

Conforme mencionamos em Pacífico, Flávio e Saquet (2005), o PVB teve sua gênese em meio às relações estabelecidas pelo Sindicato dos Trabalhadores no Comércio de Francisco Beltrão, que articulava com outras instituições a elaboração de uma proposta inicial para atuação envolvendo segmento de população vulnerável em termos econômicos e de segregação urbana, na cidade de Francisco Beltrão.

Nas articulações institucionais já se delineava, aos poucos, a constituição da equipe de trabalho. Todavia, o PVB se confirmaria e se reforçaria no interior do movimento de paralisação acadêmica, realizado em 2001, no qual a própria Unioeste, através de docentes envolvidos na greve, sensibilizou-se em perceber e dar respostas para uma demanda com relação a sua própria atuação para além do ensino e da pesquisa. Essa demanda reforçou a necessidade de se repensar a Universidade no que tange ao alcance e aos limites de sua atuação, pois historicamente ela tem pautado suas ações, essencialmente, na pesquisa e no ensino.

Após algumas reuniões realizadas entre representantes das entidades (já inicialmente mencionadas) que viriam a dar sustentação ao projeto, no final do ano 2001, pautou-se a decisão de empreendermos uma visita a dois bairros da periferia pobre da cidade de Francisco Beltrão, quais sejam: bairros São Francisco e Júpiter. O fito era fazermos a escolha de um desses bairros a partir do critério de maior vulnerabilidade social e de condições espaciais apresentadas (carências de infraestrutura urbana etc.). Tal "recorte" se explica pelas limitações ostentadas pelas entidades para o trabalho que se configurava.

Ao cabo das "visitas prévias de campo" efetivadas em ambos os bairros, fomos tendendo a construir a proposta com os moradores do bairro São Francisco, pois lá havia uma série de problemas, como falta de rede de esgoto, de atividades de lazer, de posto de saúde, de passeios para pedestres, além de flagrantes carências ligadas à ausência de calçamento nas ruas, à existência de casas localizadas sobre nascentes ou nas proximidades de sangas, bem como irregularidades na apropriação dos terrenos, entre outros pontos evidenciados. Um fator que também concorreu para 
favorecer a escolha do bairro São Francisco foi a existência de uma associação de moradores composta por pessoas comprometidas com as gentes do local.

Quando fizemos o primeiro estudo do mencionado bairro, concluído no final de 2002, um dos primeiros passos adotados foi tecer algumas análises fundamentais fitando "mapear" quais prioridades deveriam guiar nossas ações. Consoante mencionamos em Pacífico, Flávio e Saquet (2005), verificamos que a média da maioria das famílias era de quatro pessoas por residência. Do total de entrevistados (144 famílias), 53\% das famílias tinham apenas um trabalhador e 30\% tinham dois trabalhadores. As principais atividades exercidas pelas mulheres, tidas como profissionais, eram: domésticas, zeladoras, diaristas, costureiras; algumas realizavam trabalhos de natureza artesanal (pinturas). Quanto às profissões dos homens, contemplavam serviços tais como: serventes de pedreiros, pedreiros, mecânicos, pintores, marceneiros e metalúrgicos. Entre os questionados, 118 (portanto, um número bastante expressivo) tinham a renda média familiar (mensal) inferior a três salários mínimos!

A situação da população em tela, sucintamente descrita, exigia, evidentemente, uma parceria firme e arrojada por parte dos integrantes (entidades) abrangidos pelo projeto. Exigia o envolvimento de todos em ações com os conteúdos da qualidade de vida e justiça social, a partir da adoção de princípios como solidariedade e participação. Diante de tal situação, as entidades abraçaram o projeto assim se definindo:

[...] optamos pelo bairro São Francisco em virtude das condições precárias de vida de boa parte dos moradores. Na sequência, os contatos foram acirrados e, aos poucos, encaminhamos a parceria com a Associação de Moradores do Bairro São Francisco e iniciamos as atividades de sensibilização e envolvimento de moradores. Para tanto, não fizemos convênio ou outro tipo de contrato por escrito. Logo, firmamos outras parcerias com representações importantes dos moradores do bairro: Grupo de Jovens, Clube de Mães, Igreja Católica, entre outras (PACÍFICO, FLÁVIO e SAQUET, 2005, p. 29).

Quanto à receptividade dos moradores aos integrantes (representantes das entidades) envolvidos no PVB, vale observar um ponto interessante. Inicialmente, muitos moradores se mostraram ressabiados, desconfiados da idoneidade e seriedade dos propósitos e interesses nele subjacentes. É que, via de regra, as "promessas de ajuda" vindas de atores externos ao bairro geralmente se identificavam como ações de "interesse político". Como "obras" de candidatos a vereador, prefeito, deputado que amiúde não passavam mesmo de "promessas".

Todavia, à medida que, paulatinamente, as atividades propostas pelas entidades para serem realizadas para e com os moradores foram ganhando concretude, contribuíam para ganhar a confiança das gentes do bairro, que nele foram se inserindo. E então o projeto foi definitivamente se firmando. 
Assim, vencida a etapa referente a "ganhar a confiança dos moradores", o projeto foi sendo edificado e executado, de modo que as principais atividades realizadas durante seu desenvolvimento foram as seguintes:

a) Reuniões das pessoas interessadas em construir o projeto: no Sindicato dos Trabalhadores no Comércio e no bairro São Francisco. Nesses momentos, buscávamos discutir conjuntamente para deliberarmos sobre o que pretendíamos fazer. Tais espaços de diálogos entre os integrantes do projeto foi ponto fecundo para estirarmos as bases de nossas ações.

b) Formação da coordenação geral do PVB.

c) Reuniões das equipes de trabalho para debater e definir as atividades que seriam realizadas.

d) Realização do primeiro estudo sobre a realidade do bairro com o envolvimento direto de moradores do próprio bairro. Foi realizada a aplicação de questionários em 144 famílias, extraindo dados que nos ajudavam a "mapear" aspectos dos moradores referentes a: origens (de onde vieram: município, estado; rural ou urbana, tentando identificar as motivações de eventuais migrações); faixas etárias; ocupações e rendas; enfermidades existentes; condições das casas/lotes (tamanhos; materiais e estado de conservação; se próprios, alugados ou cedidos; se em ocupações irregulares); problemas ligados ao lazer; se os moradores apresentam identificação ou não com o lugar/bairro.

e) Após coletados, os dados foram tabulados. E, na sequência, preparamos uma apresentação detalhada dos dados aos moradores do bairro. Após a apresentação, seguiu-se um debate com análises acerca dos seus significados, efetivadas pela equipe coordenadora do projeto em diálogo com os moradores.

f) Efetivação de reuniões em duas das principais ruas do bairro, reunindo moradores para ouvilos sobre as demandas e reunir informações para a elaboração do diagnóstico.

g) Realização de assembleias com os moradores do bairro para definir as prioridades do projeto.

h) Realização de dinâmicas de grupo, dividindo os participantes (das assembleias) em pequenos grupos para que discutissem os problemas do bairro e imaginassem (a partir dos sonhos dos moradores) uma vida melhor. Este passo possibilitou importantes diálogos entre moradores e representantes das instituições parceiras, permitindo extrair deles sugestões de ações necessárias no âmbito do projeto.

i) Discussão e aprovação do plano de ações, a partir das prioridades eleitas, nas discussões das assembleias.

j) Definição de um logotipo para o projeto. Com a preocupação de que ele fosse verdadeiramente abraçado pelos moradores, decidimos que fosse feito um logotipo. Para envolver os jovens nas ações do projeto, ficou sob responsabilidade do grupo de jovens católicos do bairro São Francisco a confecção do logotipo, que foi escolhido mediante concurso e que contou com a participação de alguns jovens (figura 1).

k) Definição de várias parcerias no processo de concretização do PVB, pois sua dinâmica exigia, lentamente, arranjos e amarrações para que pudéssemos dar conta minimamente das demandas. Uma dessas importantes parcerias foi com a prefeitura municipal, a qual participou na efetivação de algumas ações concretizadas no projeto.

1) Realização de reuniões de planejamento para a dinamização e realização das tarefas definidas no plano de ações.

m) Avaliações do nosso trabalho e desempenho no projeto, visando aprimorar as formas de atuação dos parceiros. 


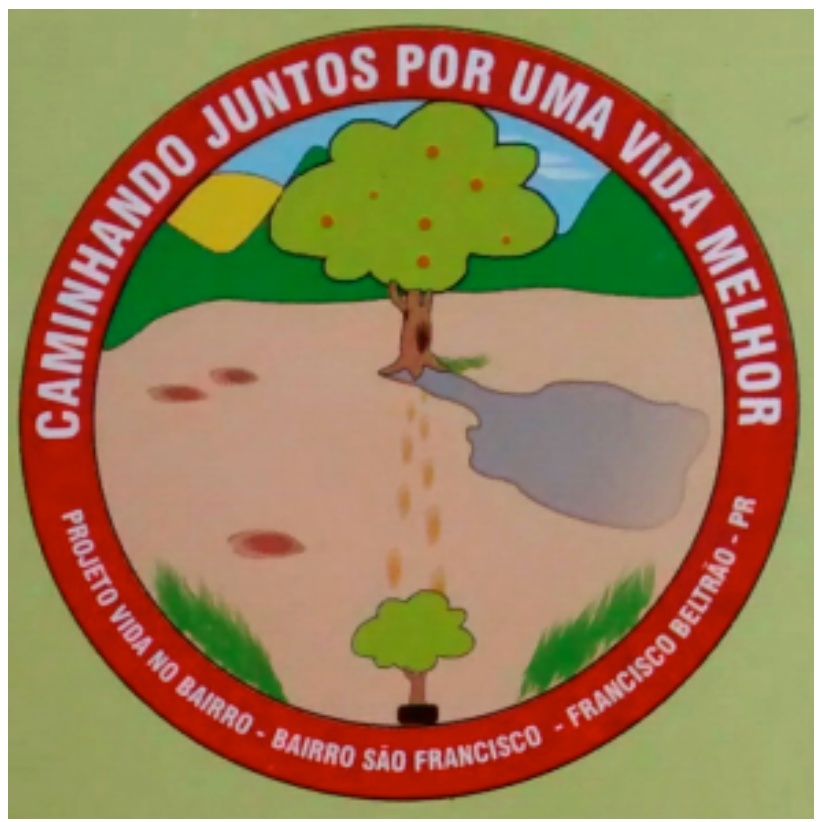

Figura 1 - Logotipo criado pelo Grupo de Jovens Católicos para o PVB.

Fonte: PACÍFICO, FLÁVIO e SAQUET (2005, capa do livro). ${ }^{6}$

Conforme afirmamos em Pacífico, Flávio e Saquet (2005, p. 48):

Desse modo, as reavaliações de estratégias e ações adotadas são ingredientes importantes na práxis cotidiana do PVB. Em nossas reuniões sempre (re)avaliamos como estão indo as coisas, se estão coerentes as formas adotadas do onde chegar, como chegar e quais ações (quem, como, quando) realizar para atingir nossas metas. Sempre que necessário, reorganizamos nosso trabalho.

Essas constantes reavaliações efetivadas pelos integrantes do projeto foram fundamentais para identificar prioridades e realizar as ações, como evidenciaremos na sequência.

\section{Definição das prioridades do PVB}

A definição das prioridades e, em seguida, a elaboração de um plano de ações (aprovados em assembleia) colocaram-se como componentes muito importantes para substantivar parte expressiva das atividades do PVB. Em síntese, as prioridades eleitas nas assembleias, compostas por integrantes do projeto e moradores do bairro, tiveram uma estruturação que se dividia nas seguintes áreas: 1) Infraestrutura; 2) Cultura e lazer; 3) Educação e formação de lideranças; 4) Divulgação, como segue ${ }^{7}$ :

\footnotetext{
${ }^{6}$ O logotipo foi utilizado como capa do livro elaborado para relatar as ações do PVB (PACÍFICO, FLÁVIO e SAQUET, 2005).

${ }^{7}$ Uma descrição bem mais completa das articulações, passos, avanços e dificuldades do PVB podem ser vistas em Pacífico, Flávio e Saquet (2005).
} 


\section{1) Infraestrutura}

- Reestabelecer as linhas e horários do transporte coletivo.

- Fazer fossas de pedra nas casas.

- Construir a rede de esgoto no bairro.

- Regularizar as propriedades dos terrenos e casas - construir casas novas através do PSH (Cohapar). ${ }^{8}$

- Atingir 100\% das famílias com água tratada.

- Identificar as casas e as ruas do bairro, numerando-as e sinalizando-as, já que sem numeração os moradores tinham dificuldades em ser localizados (correios, mercados etc.).

- Cascalhar as ruas, melhorar a drenagem das águas e calçar.

- Atingir 100\% das famílias com uma coleta de lixo feita duas vezes por semana.

- Conscientizar a população para a separação do lixo.

- Melhorar o visual do bairro.

- Repensar a ocupação de áreas de preservação.

- Iluminar as vias sem iluminação pública.

- Instalar novos telefones públicos.

- Incentivar e organizar a arborização no bairro.

- Criar um posto de saúde e uma creche.

\section{2) Cultura e lazer}

- Criar sessões culturais: teatro, filmes e documentários/cinema, músicas, gincanas e festas; rua do lazer: rodas de conversas, pintura a dedo, histórias de vida, concurso de desenho e pintura, escultura com massa de modelar e argila, caminhadas, coral, apresentação de capoeira, festa junina.

- Adquirir um terreno para a associação de moradores.

- Constituir um grupo teatral.

- Estabelecer um cronograma para o cinema no bairro.

- Organizar gincanas e festas típicas que identifiquem o bairro.

- Criar grupo de idosos.

\footnotetext{
${ }^{8}$ O PSH é um programa de subsídio à habitação de interesse social, criado pelo governo federal, em 2004. Objetiva tornar acessível a moradia para segmentos populacionais de baixa renda, via financiamento ou parcelamento habitacional de interesse social, realizados por instituições financeiras que têm parceria com o Banco Central. Cohapar é a Companhia de Habitação do Paraná, a qual era conveniada com o PSH (PALMA, 2006).
} 


\section{3) Educação e formação de lideranças}

- Viabilizar recursos para organizar cursos para formação de lideranças - atividade realizada pelo Sindicato dos Trabalhadores no Comércio e pelo STR.

- Organizar cursos profissionalizantes e para a qualidade de vida (informática, higiene de alimentos, educação ambiental, entre outros).

- Viabilizar a educação de jovens e adultos.

- Contribuir para a regularização trabalhista.

- Criar atividades alternativas de emprego e renda.

- Viabilizar, com o Colégio Estadual S. Miguel, um espaço de diálogos com os estudantes do bairro São Francisco.

- Organizar sessões de leitura de revistas e jornais.

\section{4) Divulgação}

- Construir um portal no bairro.

- Participar da programação da rádio Comunitária Anawin.

- Divulgar o projeto nos jornais da cidade.

- Definir e divulgar o logotipo do PVB.

\section{Plano de ações e realizações efetivadas no PVB}

Uma vez estabelecidas as prioridades, os passos seguintes foram trabalhados na formulação de um plano de ações, buscando definir como realizar as metas previstas. Em tal plano, primamos sempre por decidir: o que fazer; quem/quais (pessoas/moradores e entidades parceiras) se envolveriam nas ações; e quando se efetivariam as ações eleitas.

Desse modo, além das reuniões internas ao projeto (envolvendo integrantes/parceiros e moradores do bairro) a Coordenação Geral do PVB, amiúde em conjunto com a Associação de Moradores do bairro e outros parceiros passaram a realizar diversas reuniões com autoridades e representantes de entidades, os quais eram visados como importantes parceiros para a realização de pontos específicos eleitos pelos moradores do bairro.

Assim, eram comuns e constantes a realização de reuniões com: prefeito municipal; secretário de urbanismo; assessorias de deputados; representantes de entidades: Cohapar Companhia de Habitação do Paraná; Senge (Sindicato dos Engenheiros); CEF (Caixa Econômica 
Federal); representantes de Senai (Serviço Nacional da Indústria), Sebrae (Serviço Brasileiro de Apoio às Micro e Pequenas Empresas), Senac (Serviço Nacional do Comércio), Cebja (Centro Estadual de Educação Básica para Jovens e Adultos), Unioeste (Universidade Estadual do Oeste do Paraná), dentre outras.

A partir de tais ações, conseguiu-se obter vários avanços e conquistas para o bairro, como arrolamos adiante, por área:

\section{Infraestrutura}

- Mediante solicitação feita à empresa de ônibus que atua na cidade, houve o restabelecimento das linhas e horários do transporte coletivo, sendo que a forma como fora atendido o pedido se aproximava do modo demandado pelos moradores.

- Com o importante apoio para questões jurídicas, oriundo do Curso de Direito da Unioeste - Francisco Beltrão, conseguiu-se regularizar as propriedades dos terrenos e casas dos moradores que se apresentaram com tal demanda.

- Após reuniões realizadas com o prefeito, a quem levamos constantes reivindicações, a Prefeitura Municipal de Francisco Beltrão implementou um projeto para identificar e numerar as casas e ruas do bairro.

- Em relação ao problema da separação do lixo, foi feita atividade com a entrega de fôlderes informativos, produzidos e distribuídos aos moradores do bairro, por acadêmicos da Unioeste.

- Quanto à iluminação das vias sem iluminação pública ou mal iluminadas, a Prefeitura Municipal de Francisco Beltrão concretizou atividade contemplando tal reivindicação.

\section{Cultura e lazer}

Nessa área, o PVB também conseguiu alguns avanços:

- Realização de um curso de formação de lideranças, com participação de docentes da Unioeste e lideranças de alguns sindicatos (Sindicato dos Empregados no Comércio, Sindicato dos Trabalhadores Rurais).

- Efetivação de um curso sobre boas práticas de alimentação, ministrado por professores do curso de Economia Doméstica da Unioeste.

- Realização de um curso de violão popular que contemplou algumas crianças do bairro.

- A aquisição de um terreno para a associação de moradores foi uma das grandes reivindicações do projeto, tendo como principal aliada a Associação de Moradores do Bairro São Francisco, pois fora pensado como de fundamental importância para o bairro a fim de sediar as 
reuniões da associação de moradores e também para ser utilizado como local de encontro, passeio, jogos etc. Face aos trâmites político-burocráticos, tal reivindicação somente foi atendida alguns anos depois, quando o projeto já havia findado. Todavia, a semente plantada deu fruto...

\section{Educação e formação de lideranças}

- Criação do laboratório de informática, em parceria com a Secretaria do Trabalho e Ação Social, a qual cedeu computadores para serem utilizados em curso de computação, dados aos moradores do bairro.

- Implementação de um Curso de Pintura em Tecido.

- Aquisição de uma TV de 29", a ser utilizada em cursos e atividades culturais (filmes, documentários) $)^{9}$, com recursos auferidos com uma deputada estadual.

- Realização do curso de Produção de detergente, sabão e xampu, oferecido a 29 pessoas, sob a coordenação de professora do curso de Economia Doméstica da Unioeste.

\section{Divulgação}

- Foi efetivada a produção de um logotipo do PVB, ação já mencionada anteriormente, cuja criação foi protagonizada pelo grupo de jovens católicos do bairro.

- O PVB conseguiu um horário semanal na Rádio Comunitária Anawin com o fim de problematizar os problemas/necessidades do bairro e divulgar as ações do PVB. Tal programa (intitulado Programa Vida no Bairro) contava com a participação de moradores do bairro São Francisco e convidados para debater questões vivenciadas por populações urbanas (saúde, habitação, higiene, qualidade ambiental, educação etc.);

- Foram elaborados e apresentados em alguns eventos de extensão universitária o histórico de organização e de ações efetivadas pelo PVB.

Desse modo, a partir de tal organização e ação, o PVB deu a sua contribuição histórica aos moradores do bairro São Francisco. Diante de nossa exposição, atualizamos e ratificamos nosso desejo

\footnotetext{
9 "Em 20/11/2004, um sábado à noite, passamos o primeiro filme, escolhido pela própria comunidade. Identificado como raiz do nome dado ao próprio bairro, os moradores escolheram assistir ao filme que trata da vida de São Francisco de Assis. Assim, na data mencionada, foi visto o filme "Irmão sol, irmã lua". Por ocasião da Semana Santa, em 23/03/2005 foi passado outro filme, também escolhido pela comunidade, sobre a vida, paixão e morte de Jesus Cristo: O Evangelho Segundo Mateus. E está acordado que será deliberado em reuniões que virão a acontecer a escolha de filmes e datas para próximas exibições a fim de animar e enriquecer os conhecimentos dos moradores do bairro" (PACÍFICO, FLÁVIO e SAQUET, 2005).
} 
E mais, a própria forma de gestão e condução do PVB tem ensinado e incentivado a construção da cidadania, da organização popular, da autoiniciativa. Isso é um dos principais avanços do projeto, pois estamos anulando, aos poucos, o tradicional clientelismo, sempre presente na vida cotidiana (PACÍFICO, FLÁVIO e SAQUET, 2005, p. 66).

Nosso desejo é de que muitos outros projetos similares ao PVB surjam em nossas universidades, fitando dar sua contribuição em termos de apontar/(re)criar/(re)inventar soluções para a sempre presente questão urbana brasileira, aqui entendida como uma problemática de desenvolvimento territorial que precisa, obviamente, ser sustentável o máximo possível.

\section{Considerações finais}

A experiência do Projeto Vida no Bairro foi muito importante como práxis cooperada entre distintas pessoas que moram na cidade de Francisco Beltrão. Nela, aprendemos e ensinamos, ajudamos e fomos auxiliados, conhecemos melhor a cidade e tentamos socializar a sua forma de organização, revelando sujeitos dominantes, contradições e conflitualidades efetivadas historicamente. O vai e vem das atividades realizadas, nas reuniões e assembleias, planejando, debatendo e revendo quando necessário, foi extremamente profícuo e adequado para atividades desta natureza, pois o processo é permeado por novidades e contratempos, por descontinuidades que nos condicionaram constantemente a avaliar e ajustar os procedimentos escolhidos e as decisões tomadas, especialmente a partir das dificuldades encaradas diante de um Estado muito pouco sensível e voltado para a resolução dos problemas tão sérios que existem na cidade de Francisco Beltrão em termos de saneamento, habitação, ocupações irregulares, transporte etc.

As atividades do PVB reforçaram a ideia de que a mobilização, a organização e a luta precisam ser contínuas e realizadas COM as gentes da cidade (e do campo), envolvendo o máximo possível de parceiros diante da complexidade atingida atualmente pelo urbano (e pelo rural). Há uma miríade de componentes, sujeitos e processos, de desigualdades e diferenças, territorialidades e temporalidades que precisam ser considerados em processos de pesquisa e cooperação como esse que efetivamos. Portanto, a compreensão que tivemos da cidade e do urbano como território foi bastante adequada e profícua.

Ao mesmo tempo, temos clareza de que em outras experiências desta natureza precisaremos trabalhar ainda mais para tentar superar limites como os que tivemos no PVB, tais como a diversidade cultural e política dos moradores da cidade (e do campo); a fragilidade da formação política; as precariedades existentes em termos de habitação, saneamento básico, ocupações 
(irregulares) e de trabalho; as fragilidades das administrações públicas em relação às precariedades e necessidades dos moradores, as constantes tentativas de intervenção político-partidárias etc.

Para tanto, acreditamos numa abordagem territorial histórico-crítica, relacional, reticular e pluridimensional como orientação teórico-metodológica para identificar, apreender, compreender, representar, explicar e atuar em processos de transformação social, tentando cooperar participando diretamente na construção e concretização dos projetos de organização política e desenvolvimento de base local.

Conforme já destacamos em Saquet (2014), precisamos efetivar uma praxe de pesquisa, ensino e extensão de fato dialógica, respeitosa e participativa, tanto com os sujeitos estudados e com os quais trabalhamos quanto no meio acadêmico, dentro e fora da sala de aula. Ser professor, pesquisador e extensionista é extremamente delicado, complexo e difícil. Não basta dominar determinadas técnicas de pesquisa, procedimentos didáticos e certos conteúdos repassados ano após ano como se fossem modelos absolutos. É preciso respeitar os sujeitos, suas escolhas, seus saberes, suas trajetórias culturais e construir com eles o conhecimento, dentro e fora da escola, cooperando em projetos e processos de desenvolvimento.

Vale ratificar que o desenvolvimento envolve práticas fomentadoras de autonomia das populações, as quais devem sempre ser vistas como sujeitos de sua própria história e destino, à medida que participam ativamente na edificação de espaços e territórios dotados de uma vida melhor para si. Assim, sendo autônomas e ativas, as populações podem protagonizar o advento de conquistas e melhorias importantes nas cidades onde habitam. E uma vez que isso ocorra, estarão contribuindo para o avanço da qualidade de vida e de mais justiça, colaborando para enriquecer a sociedade como um todo.

\section{Referências}

ARANTES, O. B. F. Uma estratégia fatal: a cultura nas novas gestões urbanas. In: ARANTES, O., VAINER, C., MARICATO, H. (Orgs.). A cidade do pensamento único: desmanchando consensos. Petrópolis: Vozes, 2000.

BEAUJEU-GARNIER, J. Geografia urbana. 2 ed. Lisboa: FCG, 1997.

BIGNANTE, E.; DANSERO, E.; SCARPOCCHI, C. (Orgs.). Geografia e cooperazione allo sviluppo. Temi e prospettive per un approccio territoriale. Milão: Franco Angeli, 2008. p. 9-26.

CARLOS, A. F. A. Diferenciação socioespacial. Cidades, v. 4, n. 6, 2007, p. 45-60. 
CORREA, R. L. O espaço urbano. São Paulo: Ática, 2004.

DANSERO, E. Geografia e cooperazione allo sviluppo. Prospettive di ricerca. In: BIGNANTE, E.; DANSERO, E.; SCARPOCCHI, C. (Orgs.). Geografia e cooperazione allo sviluppo. Temi e prospettive per un approccio territoriale. Milão: Franco Angeli, 2008. p. 9-26.

DANSERO, E.; ZOBEL, B. Verso un dialogo tra comunità scientifica e comunità locale. In: Promozione della sostenibilità nel Pinerolese - Un percorso di ricerca/azione territoriale. Turim: Euro Mountains, 2007. p. 135-141.

DEMATTEIS, G. Le metafore della terra. La geografia umana tra mito e scienza. Milano: Feltrinelli, 1985.

. Per uma geografia della territorialità attiva e dei valori territoriali. In: BONORA, Paola. (Org.). Slot, quaderno 1. Bologna: Baskerville, 2001. p. 11-30.

FREIRE, P. Pedagogia da autonomia. Saberes necessários à prática educativa. São Paulo: Paz e Terra, 2011 [1996].

. Pedagogia do oprimido. São Paulo: Paz e Terra, 2011 [1974].

GADOTTI, M. A escola na cidade que educa. Cadernos Cenpec, n. 1, p. 133-139, 2006.

HARVEY, D. A liberdade da cidade. Geousp, Espaço e tempo, São Paulo, n. 26, p. 09-17, 2009.

INDOVINA, F.; CALABI, D. Sull'uso capitalistico del territorio. In: LUSSO, G. (Org.). Economia e territorio. Milano: Angeli, 1974. p. 205-222.

LEFEBVRE, H. A revolução urbana. Belo Horizonte: Editora UFMG, 2008b (1970).

. Espaço e política. Belo Horizonte: Editora UFMG, 2008a (1972).

. Lógica formal. Lógica dialética. Rio de Janeiro: Civilização Brasileira, 1995 [1969].

. O direito à cidade. São Paulo: Moraes, 1991.

MAGNAGHI, A. Il territorio nella crisi. Quaderni del territorio, anno 1, n. 1. Milano: Celuc Libri, 1976. p. 15-29.

MARX, K. Teses sobre Feuerbach. In: MARX, K.; ENGELS, F. A ideologia alemã (Feuerbach). São Paulo: Hucitec, 1991. p. 11-14.

OTH, V. O desenvolvimento: indicadores e tentativa de avaliação. Revista de Geografia, v. 14, p. 79-114, 1997.

PACÍFICO, J.; FLÁVIO, L.; SAQUET, M. Cidade, organização popular e desenvolvimento: a experiência do projeto vida no bairro. Francisco Beltrão, PR: Unioeste, 2005. 
PALMA, M. I. Segregação e políticas públicas: município de Bela Vista do Paraíso - PR. Monografia, Bacharelado em Geografia. Londrina: Universidade Estadual de Londrina, Departamento de Geociências, 2006.

QUAINI, M. Dopo la geografia.Roma: L’Espresso Strumenti, 1978.

RAFFESTIN, C. Paysage et territorialitè. Cahiers de géographie du Québec, vol. 21, n. 53-54, p. 123-134, 1977.

. Por uma geografia do Poder. São Paulo: Ática, 1993 [1980].

. Punti di riferimento per una teoria della territorialità umana. In: COPETA, C. (Org.). Esistere e dabitare. Prospettive umanistiche nella geografia francofona. Milano: Angeli, 1986. p. 75-89.

SANTOS, M. Espaço e método. São Paulo: Nobel, 1997.

. O espaço do cidadão. São Paulo: Nobel, 1993.

. Por uma economia política da cidade. São Paulo: Edusp, 2009.

. Por uma outra globalização - Do pensamento único à consciência universal. Rio de Janeiro: Record, 2006.

. Território e sociedade: entrevista com Milton Santos. São Paulo: Editora Fundação Perseu Abramo, 2000. Entrevista concedida a Odette Seabra, Mônica de Carvalho e José Corrêa Leite.

SAQUET, Marcos. Abordagens e concepções de território. São Paulo: Expressão Popular, 2007.

- O desenvolvimento numa perspectiva territorial, multidimensional e democrática. Revista Resgate, Campinas, vol. 19, n. 21, p. 5-15, 2011 b.

. Participação social em territórios de identidade e desenvolvimento numa práxis dialógica e cooperada. In: SILVA, O.; SANTOS, E.; COELHO Neto, A. (Orgs.). Identidade, território e resistência. Rio de Janeiro: Consequência, 2014. p. 11-36.

. Por uma Geografia das territorialidades e das temporalidades: uma concepção multidimensional voltada para a cooperação e para o desenvolvimento territorial. São Paulo: Outras Expressões, 2011a.

SAQUET, M; DANSERO, E.; CANDIOTTO, L. (Orgs.). Geografia da e para a cooperação ao desenvolvimento territorial: experiências brasileiras e italianas. São Paulo: Outras Expressões, 2012.

SOUZA, M. L. Mudar a cidade: uma introdução crítica ao planejamento e à gestão urbanos. 4 ed. Rio de Janeiro: Bertrand Brasil, 2006.

TEIXEIRA, J. P. Cidade democrática: ensaios de autonomia e democracia nas cidades do século XXI. Florianópolis: Cidade Futura, 2004. 
VAZQUEZ, A. Filosofia da práxis. Rio de Janeiro: Paz e Terra, 1990 [1977].

WILLIAMS, R. O campo e a cidade: na história e na literatura. São Paulo: Companhia das Letras, 2011 [1973].

Artigo recebido em 18/06/2015. Aceito para publicação em 18/08/2015. 